\title{
Correction to: The links between students' relationships with teachers, likeability among peers, and bullying victimization: the intervening role of teacher responsiveness
}

\author{
Claudio Longobardi ${ }^{1}$ (D) Serena Ferrigno ${ }^{1} \cdot$ Giulia Gullotta $^{1} \cdot$ Tomas Jungert $^{2}$. \\ Robert Thornberg ${ }^{3}$ - Davide Marengo ${ }^{1}$ (D) \\ Received: 6 April 2021 /Accepted: 6 April 2021/ \\ Published online: 21 April 2021 \\ C Instituto Universitário de Ciências Psicológicas, Sociais e da Vida 2021
}

\section{Correction to: European Journal of Psychology of Education https://doi.org/10.1007/s10212-021-00535-3}

The original version of the article unfortunately contained errors.

The e-mail of the corresponding authors was misspelled.

Many references were included in anonymized form.

The online version of the original article can be found at https://doi.org/10.1007/s10212-021-00535-3

\author{
Claudio Longobardi \\ claudio.longobardi@unito.it \\ Serena Ferrigno \\ serena.ferringo@edu.unito.it \\ Giulia Gullotta \\ giulia.gullotta@edu.unito.it \\ Tomas Jungert \\ tomas.jungert@psy.lu.se \\ Robert Thornberg \\ robert.thornberg@liu.se \\ Davide Marengo \\ davide.marengo@unito.it
}

Extended author information available on the last page of the article 
Publisher's note Springer Nature remains neutral with regard to jurisdictional claims in published maps and institutional affiliations.

\section{Affiliations}

Claudio Longobardi $^{1} \cdot$ Serena Ferrigno ${ }^{1} \cdot$ Giulia Gullotta $^{1} \cdot$ Tomas Jungert $^{2} \cdot$ Robert Thornberg $^{3} \cdot$ Davide Marengo $^{1}$

1 Department of Psychology, University of Turin, Via Verdi, 10, 10124 Turin, TO, Italy

2 Department of Psychology, University of Lund, Lund, Sweden

3 Linköping University, Linköping, Sweden 